\title{
Direct Hydrogenation of a Broad Range of Amides under Base- free Conditions using an Efficient and Selective PNN-Ru(II) catalyst
}

\begin{abstract}
Zheng Wang, ${ }^{[a],[b],[c]}$ Yong $\mathrm{Li}^{\left[{ }^{[a]}\right.}$ Qing-bin Liu, ${ }^{*},[a]$ Sun*,[b],[c]

Abstract: The ruthenium(II) complex, $\left[\right.$ fac- $\left.-\mathrm{PN}_{\mathrm{H}} \mathrm{N}\right] \mathrm{RuH}\left(\eta^{1}-\mathrm{BH}_{4}\right)(\mathrm{CO})$ (B) $\left(\mathrm{PN}_{\mathrm{H}} \mathrm{N}=8\right.$-(2-diphenylphosphinoethyl)-aminotrihydroquinoline), serves as a highly versatile and effective catalyst (loadings of 0.1 - 1 mol\%) capable of selectively hydrogenating a multitude of amides, including primary, secondary and tertiary, to give their corresponding alcohols and amines in high yields under base-free conditions. All products were confirmed by GC and GC-MS.
\end{abstract}

Amines can be deemed key intermediates in the chemical industry that can be employed in a diverse range of applications including as dyes, drugs, agrochemicals, plastics, surfactants, textiles through to uses in the paper industry. ${ }^{1}$ Traditionally, amines are prepared by the hydrogenation of amides using stoichiometric or excess amounts of metal-hydride reagents $\left(\mathrm{LiAlH}_{4}, \mathrm{NaBH}_{4}\right),{ }^{2}$ boranes ${ }^{3}$ or silanes; ${ }^{2,4}$ this synthetic approach being largely driven by the ready availability of the precursor amides obtainable through chemical and biomass processes. ${ }^{5}$ Nevertheless, one limitation of this type of hydrogenation is the formation of by-products that can be toxic in nature which in turn poses problems with disposal. ${ }^{2,6}$ As an alternative, the direct hydrogenation of amides into amines using molecular hydrogen in the presence of a suitable transition metal catalyst presents a more environmentally friendly method. ${ }^{2}$ However, the low electrophilicity of the carbonyl carbon, and consequent high thermodynamic and kinetic stability, renders this class of carboxylic derivative ${ }^{2,7 a}$ difficult to hydrogenate and as a result quite forcing conditions (e.g., higher temperatures and pressures) tend to be required. Unsurprisingly heterogeneous catalysts have led the way with numerous systems developed, ,2,5a,8 nonetheless these more robust systems can suffer from incompatibility problems associated with functional group intolerance. Consequently, there has been interest in developing homogeneous variants that can operate under milder conditions whilst offering more control on the hydrogenation process. ${ }^{6,7}$ Indeed a wide variety of molecular catalysts have been reported for amide hydrogenation with two types of reaction pathway prevalent namely de-oxygenative hydrogenation ( $\mathrm{C}-\mathrm{O}$ cleavage, pathway A) or de-aminative hydrogenation ( $\mathrm{C}-\mathrm{N}$ cleavage, pathway B) (Scheme 1). ${ }^{2,9}$

[a] Z Wang, Y. Li, Prof Q.-B liu.

College of Chemistry and Material Science, Hebei Normal University, Shijiazhuang 050024, China

E-mail: liuqingb@sina.com

[b] Z. Wang, Prof. G. A. Solan, Y. Ma, Prof. W.-H. Sun. Key Laboratory of Engineering Plastics and Beijing National Laboratory for Molecular Science, Institute of Chemistry, Chinese Academy of Sciences, Beijing 100190, China

E-mail:whsun@iccas.ac.cn;gas8@le.ac.uk

[c] Z. Wang, Prof. W.-H. Sun CAS Research/Education Center for Excellence in Molecular Sciences, University of Chinese Academy of Sciences, Beijing 100049, China

[d] Department of Chemistry, University of Leicester, University Road, Leicester LE1 7RH, UK

Supporting information for this article is given via a link at the end of the document.
Gregory A. Solan,, ${ }^{*}[\mathrm{~b}],[\mathrm{d}]$ Yanping Ma, ${ }^{[b]}$ Wen-Hua

A decade ago, Cole-Hamilton and co-workers reported the first homogeneous hydrogenation of amides using $\mathrm{Ru}(\mathrm{acac})_{3} /$ triphos (triphos $=1,1,1$-tris(diphenylphosphinomethyl)ethane), ${ }^{10}$ through a predominantly de-oxygenative hydrogenation pathway that displayed low selectivity. To enhance this selectivity, the presence of an acid as co-catalyst has been disclosed. ${ }^{11}$ Subsequently, selective $\mathrm{C}-\mathrm{N}$ bond hydrogenation of amides has been demonstrated using catalysts developed by the groups of Milstein, ${ }^{12}$ Ikariya, ${ }^{13}$ Saito, ${ }^{14}$ Bergens, ${ }^{15}$ Mashima, ${ }^{16}$ Beller ${ }^{17}$ and others, ${ }^{18}$ in which the majority of these examples require an excess amount of base to ensure good activities. In a manner akin to Noyori's work on metal-mediated carbonyl group hydrogenation under base-free conditions, ${ }^{19}$ two examples have emerged that can operate under similar such conditions. ${ }^{150,17 a}$ However, these base-free catalysts systems reported by Bergen and Beller are limited in their substrate scope with some amides (e.g., primary) not conducive to reduction. Hence, there is a considerable drive to develop a general catalyst capable of efficiently hydrogenating a multitude of common amide-types into amines without the use of base and under mild conditions.

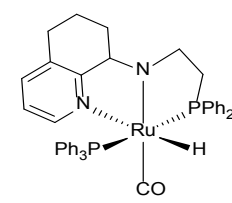

A

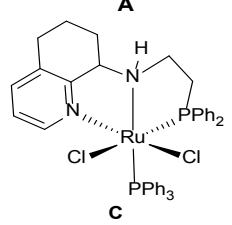

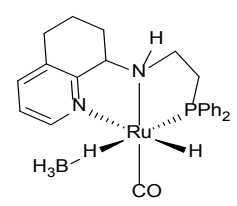

B

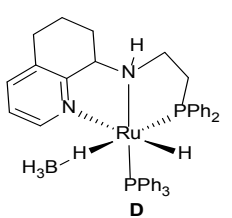

Chart 1. Ruthenium(II) complexes, A - D, to be investigated as catalysts for the hydrogenation of amides in this study

In recent work we have found the PNN-ruthenium(II) complex, [fac-PNN]RuH( $\left.\mathrm{PPh}_{3}\right)(\mathrm{CO})(\mathrm{PNN}=8$-(2-diphenylphosphinoethyl)amidotrihydroquinoline) (A, Chart 1) to be highly efficient in the coupling-cyclization of $\mathrm{y}$-amino alcohols with secondary alcohols with catalyst loadings of as low as $0.025 \mathrm{~mol} \% .{ }^{20}$ Furthermore, A 
and its derivative $\left[\mathrm{fac}^{-} \mathrm{PN} \mathrm{N}_{\mathrm{H}} \mathrm{N}\right] \mathrm{RuH}\left(\eta^{1}-\mathrm{BH}_{4}\right)(\mathrm{CO})(\mathrm{B})\left(\mathrm{PN}_{\mathrm{H}} \mathrm{N}=8-(2-\right.$ diphenylphosphinoethyl)aminotrihydroquinoline) (Chart 1) could promote the catalytic hydrogenation of esters in the presence of a $5 \mathrm{~mol} \%$ amount of $\mathrm{NaBH}_{4}{ }^{21}$ Moreover, both $\mathbf{A}$ and $\mathbf{B}$ along with the related ruthenium(II) complexes, $\left[\right.$ fac- $\left.-\mathrm{PN}_{\mathrm{H}} \mathrm{N}\right] \mathrm{RuCl}_{2}\left(\mathrm{PPh}_{3}\right)$ (C) and $\left[\right.$ fac $\left.-\mathrm{PN}_{\mathrm{H}} \mathrm{N}\right] \mathrm{RuH}\left(\eta^{1}-\mathrm{BH}_{4}\right)\left(\mathrm{PPh}_{3}\right)$ (D) (Chart 1), were capable of the acceptorless dehydrogenation of alcohols with high conversions. ${ }^{22}$ Given the adaptability of $\mathbf{A}-\mathbf{D}$ to both dehydrogenation and hydrogenation processes, we were interested in exploring their potential as catalysts for the hydrogenation of the more challenging amides.

To assess the catalytic activity, the PNN-bound ruthenium complex $\mathbf{A}$ was in the first instance evaluated in amide hydrogenation using benzanilide as the test substrate (Table 1). Using the same conditions as previously employed in ester hydrogenation ${ }^{21}$ (catalyst loading $=0.05 \mathrm{~mol} \%, \mathrm{p}\left(\mathrm{H}_{2}\right)=50$ bar, 5 mol\% of $\mathrm{NaBH}_{4}, \mathrm{~T}=120^{\circ} \mathrm{C}$, solvent $=\mathrm{THF}, \mathrm{t}=24$ hours), only $12 \%$ of benzanilide was hydrogenated (entry 1 ). However, with a catalyst loading of $1 \mathrm{~mol} \%$, the conversion increased with $45 \%$ of the substrate being reduced to benzyl alcohol (42\%) and aniline (43\%) (entry 2). Doubling the amount of the base, $\mathrm{NaBH}_{4}$, to $10 \mathrm{~mol} \%$ had the effect of increasing the conversion to $65 \%$ (entry 3). More notably, running the reaction in $i-\mathrm{PrOH}$ instead of THF under the same conditions, afforded benzyl alcohol and aniline in quantitative yield (entry 4), while performing the reaction in the complete absence of $\mathrm{NaBH}_{4}$ in $i-\mathrm{PrOH}$ led to conversions of $80 \%$ and $85 \%$ in 24 and 36 hours, respectively (entry 5).

Using B (1 mol\%) in place of $\mathbf{A}$ with the quantity of $\mathrm{NaBH}_{4}$ set at $10 \mathrm{~mol} \%$, the reaction afforded quantitative yields of benzyl alcohol and aniline in 16 hours (entry 6). Substituting $\mathrm{NaBH}_{4}$ with $10 \mathrm{~mol} \%$ of $t$-BuOK or KHMDS (potassium bis(trimethylsilyl)amide), resulted in $95 \%$ and $98 \%$ of benzanilide being reduced over 20 hours, respectively (entries 7 and 8). Significantly, when B was used in the absence of base, quantitative yields of benzyl alcohol and aniline were obtained at 50 bar of $\mathrm{H}_{2}$ and $120^{\circ} \mathrm{C}$ in

Table 1. Optimization of the reaction conditions for the hydrogenation of benzanilide with ruthenium complexes, A - D

$$
\underset{\mathrm{H}^{-}}{\stackrel{\mathrm{O}}{\mathrm{N}_{\mathrm{N}^{-}}} \stackrel{\mathrm{Ah}-\mathrm{D}, \mathrm{H}_{2}(50 \mathrm{bar})^{\mathrm{b}}, \mathrm{T}\left({ }^{\circ} \mathrm{C}\right)}{\text { base, } \mathrm{t}(\mathrm{h}), \text { solvent }}} \mathrm{Ph} \frown \mathrm{OH}+\mathrm{Ph}_{-\mathrm{NH}_{2}}
$$

\begin{tabular}{|c|c|c|c|c|c|c|c|c|c|}
\hline Entry & Catalyst & Loading (mol\%) & Solvent & $\mathrm{T}\left({ }^{\circ} \mathrm{C}\right)$ & Base (x mol\%) & $t(h)$ & Conv. $(\%)^{c}$ & alcohol $(\%)^{c}$ & amine $(\%)^{c}$ \\
\hline $1^{d}$ & A & 0.05 & THF & 120 & $\mathrm{NaBH}_{4}(5)$ & 24 & 12 & 12 & 10 \\
\hline 2 & A & 1 & THF & 120 & $\mathrm{NaBH}_{4}(5)$ & 24 & 45 & 42 & 43 \\
\hline 3 & A & 1 & THF & 120 & $\mathrm{NaBH}_{4}(10)$ & 24 & 65 & 64 & 63 \\
\hline 4 & A & 1 & $i-\mathrm{PrOH}$ & 120 & $\mathrm{NaBH}_{4}(10)$ & 18 & 100 & $>99$ & $>99$ \\
\hline 5 & A & 1 & $i$-PrOH & & none & $\begin{array}{l}24 \\
36\end{array}$ & $\begin{array}{l}80 \\
85\end{array}$ & $\begin{array}{l}78 \\
84\end{array}$ & $\begin{array}{l}75 \\
83\end{array}$ \\
\hline 6 & B & 1 & $i-\mathrm{PrOH}$ & 120 & $\mathrm{NaBH}_{4}(10)$ & $\begin{array}{c}4 \\
16\end{array}$ & $\begin{array}{c}30 \\
100\end{array}$ & $\begin{array}{c}27 \\
>99\end{array}$ & $\begin{array}{c}28 \\
>99\end{array}$ \\
\hline 7 & B & 1 & $i-\mathrm{PrOH}$ & 120 & $t$-BuOK (10) & 20 & 95 & 94 & 93 \\
\hline 8 & B & 1 & $i$-PrOH & 120 & $\operatorname{KHMDS}^{e}(10)$ & 20 & 98 & 97 & 96 \\
\hline 9 & B & 1 & & 120 & none & $\begin{array}{c}4 \\
16\end{array}$ & $\begin{array}{c}36 \\
100\end{array}$ & $\begin{array}{c}34 \\
>99\end{array}$ & $\begin{array}{c}35 \\
>99\end{array}$ \\
\hline 10 & B & 0.1 & $i-\mathrm{PrOH}$ & 120 & none & 24 & 75 & 74 & 73 \\
\hline 11 & B & 1 & $i-\mathrm{PrOH}$ & 140 & none & 14 & 100 & $>99$ & $>99$ \\
\hline 12 & B & 1 & i-PrOH & 80 & none & 24 & 90 & 90 & 87 \\
\hline $13^{f}$ & B & 1 & i-PrOH & 120 & none & 24 & 85 & 85 & 84 \\
\hline $14^{\mathrm{g}}$ & B & 1 & $i$-PrOH & 120 & none & 24 & 45 & 43 & 42 \\
\hline $15^{\mathrm{h}}$ & B & 1 & $i-\mathrm{PrOH}$ & 120 & $\mathrm{NaBH}_{4}(100)$ & 16 & 90 & 86 & 87 \\
\hline 16 & C & 1 & $i$-PrOH & 120 & none & 24 & 45 & 43 & 44 \\
\hline 17 & D & 1 & $i-\mathrm{PrOH}$ & 120 & none & 24 & 95 & 95 & 95 \\
\hline 18 & none & 0 & $i$-PrOH & 120 & $\mathrm{NaBH}_{4}(10)$ & 24 & - & - & - \\
\hline
\end{tabular}

a Conditions: benzanilide $(1 \mathrm{mmol}), \mathbf{A}-\mathbf{D}(0.01 \mathrm{mmol})$, solvent $(30 \mathrm{~mL})$ under $\mathrm{H}_{2}(50 \mathrm{bar}){ }^{\text {b }}$ Pressure of hydrogen at room temperature in all cases. ${ }^{\mathrm{c}}$ Conversion of benzanilide and yields of benzyl alcohol and aniline were determined by GC (using hexadecane as an external standard) and GC-MS. ${ }^{d}$ The reaction was conducted with $\mathbf{B}(0.0005 \mathrm{mmol})$ and $5 \mathrm{~mol} \%$ of $\mathrm{NaBH}_{4} .{ }^{e} \mathrm{KHMDS}$ is potassium bis(trimethylsilyl)amide. ${ }^{\mathrm{f}}$ The reaction was conducted under $\mathrm{H}_{2}$ (30 bar). ${ }^{g}$ The reaction was conducted under $\mathrm{H}_{2}(10$ bar $) .{ }^{h}$ in absence of $\mathrm{H}_{2}$. 
16 hours (entry 9). Even with the catalyst loading reduced to 0.1 mol\%, B still performed to a high level allowing a $75 \%$ conversion of benzanilide in 24 hours (entry 10). Raising the temperature to $140^{\circ} \mathrm{C}$ also gave quantitative conversion over 14 hours while lowering it to $80^{\circ} \mathrm{C}$, the conversion dropped to $90 \%$ (entries 11 and 12). With the temperature restored to $120^{\circ} \mathrm{C}$, the conversion was also affected by the pressure of hydrogen employed, which decreased to $85 \%$ and $45 \%$ at 30 bar and 10 bar, respectively in 24 hours (entries 13 and 14).

With $\mathbf{C}$ and $\mathbf{D}$ as catalyst, under base-free conditions, $45 \%$ and $95 \%$ of benzanilide was hydrogenated over 24 hours, respectively (entries 16 and 17), which contrasts with quantitative conversion observed for $\mathbf{B}$ over 16 hours (entry 9). Moreover, with a stoichiometric amount of $\mathrm{NaBH}_{4}(1 \mathrm{mmol})$ but no hydrogen ( 0 bar $\mathrm{H}_{2}, \mathrm{~T}=120^{\circ} \mathrm{C}$ ), B facilitated $90 \%$ conversion of benzanilide in 16 hours. Hence $\mathrm{NaBH}_{4}$ can also serve as the source of hydrogen for the hydrogenation of amides (entry 15); this observation is entirely consistent with that found for the catalytic hydrogenation of esters by $\mathbf{A} .^{20}$ For purposes of comparison, no benzanilide was hydrogenated when the reaction was performed without any Ru-complex (entry 18). Overall these preliminary experiments (Table 1, see also $\mathrm{SI}$ Table S2) suggest that $\mathbf{B}$ is a credible catalyst for the hydrogenation of amides under base-free conditions.

As mentioned above the choice of solvent employed can have a significant effect on the conversion of benzanilide to benzyl alcohol and aniline with $i$-PrOH superior to THF when using $\mathbf{A}$. To explore more thoroughly these effects, we also probed the catalytic performance of B $(0.1 \mathrm{~mol} \%)$ under base-free conditions using a range of different solvents (Fig. 1, see Table $\mathrm{S} 3$ in the $\mathrm{SI}$ ). When $\mathrm{MeOH}$, EtOH or $i$ - $\mathrm{BuOH}$ were employed, the conversion observed over 24 hours was respectively $15 \%$, $25 \%$ and $28 \%$, notably less than that found with $i-\operatorname{PrOH}(75 \%$ over the same time period). In comparison, using $\mathbf{A}(0.1 \mathrm{~mol} \%)$, this time in the presence of $10 \mathrm{~mol}^{2} \mathrm{NaBH}_{4}$ but using $i-\mathrm{PrOH}$ as solvent,

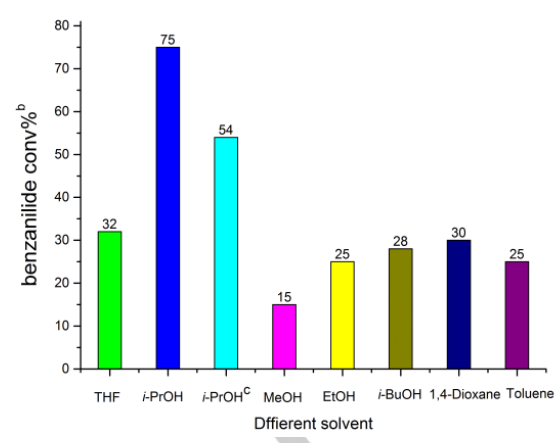

Fig. 1. Influence of solvent on the hydrogenation of benzanilide using $\mathbf{B}^{\mathrm{a}}$

a Standard reaction conditions: benzanilide $(2.5 \mathrm{mmol})$, B $(2.5 \mu \mathrm{mol})$, solvent (30 mL) under $\mathrm{H}_{2}$ (50 bar) at $120{ }^{\circ} \mathrm{C}$ in 24 hours, ${ }^{\mathrm{b}}$ Conversion of benzanilide and yields of benzyl alcohol and aniline were determined by GC (using hexadecane as an external standard) and GC-MS. ${ }^{c}$ The reaction was conducted with $\mathbf{A}(2.5 \mu \mathrm{mol}), 10 \mathrm{~mol} \%$ of $\mathrm{NaBH}_{4}$ at $120^{\circ} \mathrm{C}$ in 36 hours.

the conversion lowered to $54 \%$ in 36 hours. On the other hand, with aprotic solvents such as THF, 1,4-dioxane and toluene only $32 \%, 30 \%$ and $25 \%$ conversion of benzanilide could be achieved after 24 hours using B, respectively. Hence, $i-\mathrm{PrOH}$ proved the most suitable solvent for the transformation and following some further optimization studies (see SI, Tables S2 and S3), the best overall conditions for effective hydrogenation were established as: B $(0.1-1 \mathrm{~mol} \%), i-\mathrm{PrOH}$ as solvent, temperature of $120^{\circ} \mathrm{C}$ and 50 bar of hydrogen pressure.

Next, with a view to exploring the substrate scope of $\mathbf{B}$ as a base-free catalyst and hence its generality, we screened it for the hydrogenation of a broad range of alkyl- and aryl-substituted amides using the optimized conditions identified (Tables 2 and 3). Firstly, a family of benzanilides functionalized at either the $\mathrm{N}$-aryl or the benzoyl group was evaluated; the complete list of substrates along with hydrogenation results was collected in Table 2. Pleasingly, most of the substrates were reduced, affording excellent yields of the desired amine and/or alcohol. As a general observation, electron-withdrawing groups at the paraposition of the $\mathrm{N}$-aryl group enhanced the reactivity of the substrate. For example, the benzanilides bearing electronwithdrawing $p-\mathrm{F}, p-\mathrm{Cl}$ and $p-\mathrm{Br}$ substituents afforded quantitative yields of benzyl alcohol and the corresponding substituted aniline in 10 - 16 hours (entries 2, 4, 7). Notably the aryl bromides were tolerant to the reaction conditions with no dehalogenation products detected. Even at catalyst loadings as low as $0.1 \mathrm{~mol} \%, \mathrm{~N}$-(4-chlorophenyl)benzamide and $\mathrm{N}$-(4bromophenyl)benzamide underwent hydrogenation with high conversions over 24 hours with $>99 \%$ selectivity for $\mathrm{C}-\mathrm{N}$ bond cleavage (entries 4,7 ). In general, the benzanilides containing para-substituted halides are more easily reduced than their meta-substituted counterparts (entries 2 vs. 1 and 4 vs. 3), while increasing the number of halide substituents on the $\mathrm{N}$-aryl ring did not accelerate the reaction rate (entries 4 vs. 5 and 6). In addition, at a catalyst loading of $0.1 \mathrm{~mol} \%, \mathrm{~N}-(3,4-$ dichlorophenyl)benzamide needs a longer reaction time (40 hours) to reach a comparable conversion to that seen with $\mathrm{N}$-(4chlorophenyl)benzamide (entry 5 vs. 4). Unexpectedly, the arylsubstituted substrates containing electron-donating groups also achieved high conversions despite the decreased electrophilicity of the carbonyl carbon, however these conversions were over longer reaction times (entries 10, 12-15). Moreover, the presence of substituents with some modest steric hindrance at the meta- or ortho-positions on the aromatic ring substrates were well tolerated (entries 12 and 16). However, amides with either highly hindered $\mathrm{N}$-aryl groups (e.g., mesityl) or containing $\mathrm{N}$ pyridyl groups were not amenable to reduction (entries 11 and 17).

The hydrogenation capability of this catalytic system is not limited to aryl-substituted secondary amides (entries 18 - 22). Indeed, we have shown that primary and tertiary amides can also be reduced. For example, benzamide, 4-chlorobenzamide, 4-bromobenzamide and 4-methoxybenzamide gave reasonable conversions to their corresponding alcohols over 24 hours. It is 
Table 2. Hydrogenation of aryl-substituted amides catalyzed by $\mathbf{B}^{\mathrm{a}}$

\begin{tabular}{|c|c|c|c|c|c|c|c|c|c|}
\hline Entry & Substrate & $t(h)$ & Conv. $(\%)^{c}$ & $\begin{array}{c}\text { alcohol/amine } \\
(\% / \%)^{\mathrm{c}}\end{array}$ & Entry & Substrate & $t(h)$ & Conv. $(\%)^{\mathrm{C}}$ & $\begin{array}{c}\text { alcohol/amine } \\
(\% / \%)^{\mathrm{c}}\end{array}$ \\
\hline 1 & & 16 & 75 & $70 / 73$ & 12 & & & 86 & $85 / 84$ \\
\hline 2 & & $\begin{array}{c}16 \\
36^{\mathrm{d}}\end{array}$ & $\begin{array}{l}99 \\
75\end{array}$ & $\begin{array}{l}99 / 99 \\
75 / 72\end{array}$ & 13 & & 24 & 99 & $75 / 99$ \\
\hline 3 & & 16 & 99 & 99/99 & 14 & & 24 & 75 & $65 / 75$ \\
\hline \multirow{2}{*}{4} & & 10 & 99 & $95 / 98$ & \multirow{2}{*}{15} & & 24 & 55 & $50 / 48$ \\
\hline & & $24^{d}$ & 80 & $80 / 76$ & & & $48^{e}$ & 99 & $95 / 96$ \\
\hline 5 & & 16 & 99 & & 16 & & 24 & 95 & $95 / 90$ \\
\hline 6 & & 16 & 99 & 99/95 & 17 & & 24 & trace & nd \\
\hline \multirow{2}{*}{7} & & 10 & 99 & 99/99 & \multirow{2}{*}{18} & & \multirow{2}{*}{24} & \multirow{2}{*}{65} & \multirow{2}{*}{$65 / \mathrm{nd}$} \\
\hline & & $24^{d}$ & 85 & $85 / 83$ & & & & & \\
\hline 8 & & 10 & 99 & $99 / 99$ & $19^{f}$ & & 24 & 55 & $50 /$ nd \\
\hline 9 & & 20 & 99 & 95/92 & 20 & & 24 & 65 & $62 / \mathrm{nd}$ \\
\hline 10 & & 24 & 99 & $95 / 9$ & $21^{f}$ & & 24 & 64 & $60 /$ nd \\
\hline 11 & & 24 & $<1$ & n.d. & $22^{f}$ & & 24 & 45 & $42 / n d$ \\
\hline
\end{tabular}

a Standard reaction conditions: amide $(1 \mathrm{mmol}), \mathbf{B}(0.01 \mathrm{mmol}), i-\mathrm{PrOH}(30 \mathrm{~mL})$ under $\mathrm{H}_{2}(50 \mathrm{bar})$ in $10-48$ hours. ${ }^{b}$ Pressure of $\mathrm{H}_{2}$ at room temperature in all cases. ${ }^{\circ}$ Conversion of amide and yields of alcohol and amine were determined by GC (using hexadecane as an external standard) and GC-MS (nd $=$ not detected). ${ }^{\mathrm{d}}$ Standard reaction conditions: amide $(10 \mathrm{mmol}), \mathbf{B}(0.01 \mathrm{mmol}), i-\mathrm{PrOH}(30 \mathrm{~mL})$ under $_{2}\left(50\right.$ bar) in $24-48$ hours. ${ }^{\text {e }}$ Standard reaction conditions: amide $(10 \mathrm{mmol}), \mathbf{B}(0.5 \mathrm{mmol}), i-\mathrm{PrOH}(30 \mathrm{~mL})$ under $\mathrm{H}_{2}\left(50\right.$ bar) in 48 hours. ${ }^{f}$ The reaction temperature is $140{ }^{\circ} \mathrm{C}$

noteworthy that such unactivated primary amides have been scarcely investigated in this type of hydrogenation but, where reported, tend to require an excess of base to provide satisfactory activity. ${ }^{14,16,17 a}$

Secondly, the capacity of $\mathbf{B}$ to reduce alkyl-substituted amides was explored; the specific substrate types and the results of the hydrogenation are documented in Table 3. Acetanilide and its derivatives underwent hydrogenation in quantitative yield using B at a $1 \mathrm{~mol} \%$ loading (entries $1-5$ ). Even at $0.1 \mathrm{~mol} \%, \mathrm{~N}$ methylacetamide and $\mathrm{N}, \mathrm{N}$-dimethylacetamide could be readily hydrogenated affording high yields of ethanol and the corresponding amines after 20 hours (entries 1 and 2). Likewise, the reduction of 3-phenyl- $\mathrm{N}$-( $p$-tolyl)propanamide and $\mathrm{N}$-(4bromophenyl)-3-phenylpropanamide (entries 6 and 7 ) proceeded smoothly, while the longer chain amide, $N$-(4-bromophenyl)decanamide, gave high yields of decanol and 4-bromoaniline (entry 8). For the primary fatty amide, octanamide, hydrogenation to give octan-1-ol was more sluggish at $35 \%$ yield even with the reaction temperature raised to $140{ }^{\circ} \mathrm{C}$ (entry 9). Meanwhile, hydrogenation of the cyclic amide, $\varepsilon$-caprolactam, proceeded cleanly to afford 6-amino-1-hexanol in $98 \%$ yield (entry 10). Overall, these results reveal that alkyl-substituted amides like their aryl-amide counterparts can be readily reduced with $\mathbf{B}$ under a set of general reaction conditions.

The mechanistic details of how $\mathbf{B}$ operates in amide hydrogenation raises some intriguing questions, particularly because we have previously highlighted the cooperative role of $\mathrm{NaBH}_{4}(5 \mathrm{~mol} \%)$ in the hydrogenation of esters with the same 


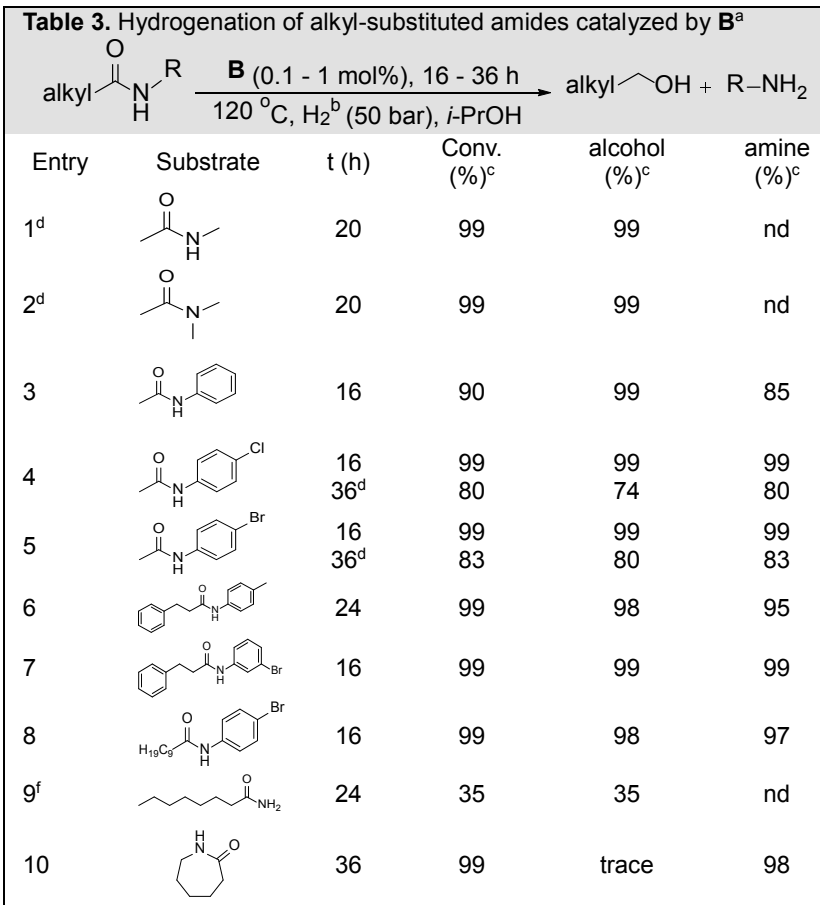

a Standard reaction conditions: amide $(1 \mathrm{mmol}), \mathbf{B}(0.01 \mathrm{mmol}), i-\mathrm{PrOH}$ (30 $\mathrm{mL})$ under $\mathrm{H}_{2}\left(50\right.$ bar) in $10-36$ hours. ${ }^{b}$ Pressure of $\mathrm{H}_{2}$ at room temperature in all cases. ${ }^{\circ}$ Conversion of amide and yields of alcohol and amine were determined by GC (using $n$-hexadecane as an external standard) and GC-MS $\left(\mathrm{nd}=\right.$ not detected) ${ }^{\mathrm{d}}$ Standard reaction conditions: amide $(10 \mathrm{mmol}), \mathbf{B}(0.01 \mathrm{mmol}), i-\mathrm{PrOH}(30 \mathrm{~mL})$ under $\mathrm{H}_{2}(50 \mathrm{bar})$ in 20 hours. ${ }^{f}$ The reaction temperature is $140^{\circ} \mathrm{C}$.

catalyst. ${ }^{21}$ Importantly, we have shown in this work that the addition of $10 \mathrm{~mol} \%$ of $\mathrm{NaBH}_{4}$ to the amide hydrogenation promoted by $\mathbf{B}$ has little or no effect on the conversion observed when compared with the reaction performed in the absence of $\mathrm{NaBH}_{4}$ (entries 6 vs. 9, Table 1). By contrast, addition of 10 mol\% of $\mathrm{NaBH}_{4}$ to an amide hydrogenation mediated by $\mathbf{A}$, conversion did show some increase (entries 4 vs. 5, Table 1) which can be attributed to the in-situ generation of $\mathbf{B}$ from $\mathbf{A} .^{20}$ The implication is that the base-free amide hydrogenation reported herein follows a modified mechanism to that seen in ester hydrogenation.

To understand the effect of amine formation on the catalytic performance of $\mathbf{B}$, we added one molar equivalent of aniline to the original ester hydrogenation using a catalyst composed of $\mathbf{A}$ and $\mathrm{NaBH}_{4}\left(50\right.$ bar $\mathrm{H}_{2}, \mathrm{~T}=120^{\circ} \mathrm{C}$ ) (Table S4 in SI). With methyl benzoate as the substrate, $\mathbf{A} / \mathrm{NaBH}_{4}$ promoted almost quantitative conversion to methyl benzoate over 24 hours (see SI, Table S4), which is significantly slower than that observed without aniline (only 4 hours). ${ }^{21}$ This would suggest that catalyst deactivation is occurring and likely by the coordination of the aniline to the ruthenium catalyst. By implication, it would therefore seem probable that those amides that proved less conducive to hydrogenation by $\mathbf{B}$ (e.g., lower conversions or slower) are inhibited by the formation of Ru-amine type species.

A proposed mechanism for the amide hydrogenation developed in this work is shown in Scheme 2. Initially, B can be converted to cis-dihydride 1 ' involving $\mathrm{BH}_{4}{ }^{-}$dissociation and the

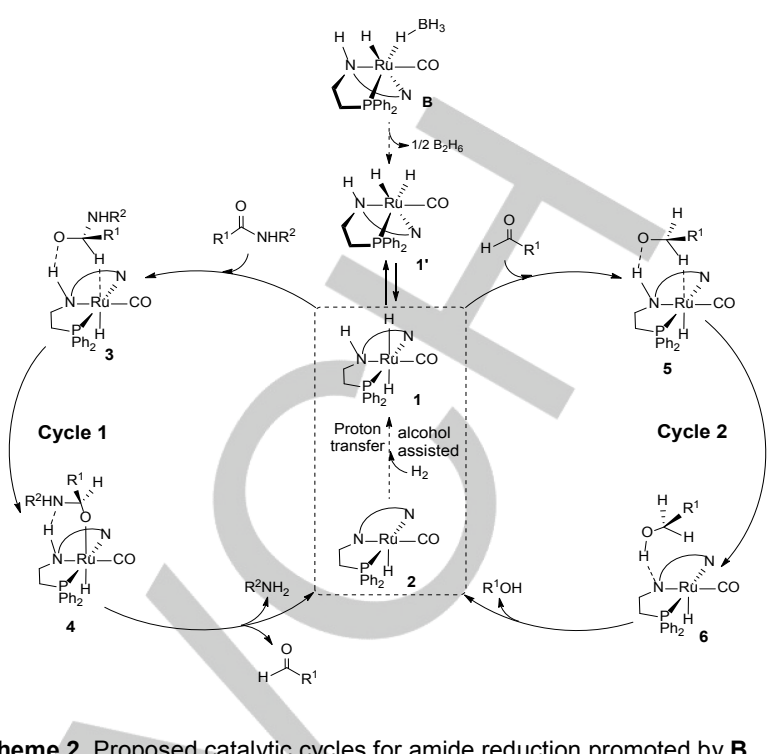

Scheme 2. Proposed catalytic cycles for amide reduction promoted by B

release of $1 / 2 \mathrm{~B}_{2} \mathrm{H}_{6}$. A fac-mer isomerization of the $\mathrm{PN}_{H} \mathrm{~N}$ ligand then ensues generating trans-dihydride 1 , which in previous work we have considered as the actual catalyst in ester hydrogenation. ${ }^{21}$ Hence, 1 can then enter two linked but distinct catalytic cycles. ${ }^{21}$ At the start of Cycle 1 , an amide molecule approaches 1 resulting in a transfer of the hydride directly from the ruthenium center to its unsaturated carbonyl carbon to form intermediate 3 via an outer-sphere bifunctional mechanism. ${ }^{2,12 a}$ 12e, 21, 23, 24 Reorganization of the $\mathrm{CH}\left(\mathrm{NHR}^{2}\right) \mathrm{R}^{1} \mathrm{O}$ anion forms Obound 4 which can then undergo elimination of a molecule of amine and aldehyde to afford 2 . The active catalyst 1 is regenerated through alcohol-assisted $\mathrm{H}_{2}$ activation. ${ }^{21,24}$ Cycle 2 represents the hydrogenation of the aldehyde to alcohol with starts with a hydride transfer from ruthenium to the unsaturated carbonyl carbon via an outer-sphere bifunctional mechanism forming intermediate $\mathbf{5}$ which can then transform into hemiacetal 6. 6 then decomposes by the release of alcohol to form 2 which can then re-form the active catalyst 1 via $\mathrm{H}_{2}$ activation.

In summary, we have demonstrated that ruthenium(II) complex $\mathrm{B}$ bearing a $\mathrm{PN}_{\mathrm{H}} \mathrm{N}$ ligand, is an effective catalyst for the hydrogenation of both aromatic and aliphatic amides including unactivated examples under base-free conditions affording selectively the corresponding alcohols and amines in high yields. The catalytic activity for the reduction of substituted-benzanilides was greatly affected by electronic, conjugative and steric effects. Electron withdrawing groups on the aromatic ring increase the reactivity while electron-donating groups decrease it. For $\mathrm{N}, \mathrm{N}$ dimethylacetamide, a very high conversion (catalyst loading = $0.1 \mathrm{~mol} \%, 99 \%$ yield) is achieved in 20 hours at $120{ }^{\circ} \mathrm{C}$. Unlike ester hydrogenation with $\mathbf{A}$, there is no evidence for cooperation between $\mathrm{NaBH}_{4}$ and $\mathbf{A}$ in the hydrogenation of amides; the function of adding $10 \mathrm{~mol} \%$ of $\mathrm{NaBH}_{4}$ is purely to form $\mathbf{B}$. 


\section{Experimental section}

General information. Unless otherwise stated, all manipulations were performed under an atmosphere of argon or using standard Schlenk techniques. Hydrogen gas (99.99\%) was purchased from Shijiazhuang Xisanjiao. Solvents were dried using standard procedures and degassed with nitrogen. For example, tetrahydrofuran (THF) was distilled over sodium/benzophenone, 1,4-dioxane was distilled over sodium and diglyme (diethylene glycol dimethyl ether) was distilled over sodium under reduced pressure. Analytical grade isopropanol, ethanol, methanol and toluene were degassed by bubbling argon through them before use. GC-MS was carried out on DSQII instrument (column: HP-5MS): injector temp. $300{ }^{\circ} \mathrm{C}$; detector temp. $300{ }^{\circ} \mathrm{C}$; column temp. $40{ }^{\circ} \mathrm{C}$; withdraw time $2 \mathrm{~min}$, then $20^{\circ} \mathrm{C} / \mathrm{min}$ to $230^{\circ} \mathrm{C}$ over $5 \mathrm{~min}$. and then 20 ${ }^{\circ} \mathrm{C} / \mathrm{min}$ to $300^{\circ} \mathrm{C}$; withdraw time $5 \mathrm{~min}$. GC analysis was carried out on an Agilent 6820 instrument using a polar capillary column (part number $19091 \mathrm{~N}-113$ HP-INNOWAX): injector temp. $300{ }^{\circ} \mathrm{C}$; detector temp. $300{ }^{\circ} \mathrm{C}$; column temp. $40^{\circ} \mathrm{C}$; withdraw time $2 \mathrm{~min}$, then $20^{\circ} \mathrm{C} / \mathrm{min}$ to 230 ${ }^{\circ} \mathrm{C}$ over $5 \mathrm{~min}$. and then $20^{\circ} \mathrm{C} / \mathrm{min}$ to $300^{\circ} \mathrm{C}$; withdraw time for $5 \mathrm{~min}$. The purity of all the amide substrates was greater than $97 \%$ and these were purchased from Beijing Innochem, Science \& Technology. CAS numbers for the amide substrates and products)are included in Table S1 of the SI. All the liquid substrates and solid substrates were used directly. Complexes A - D were prepared using previously reported routes. ${ }^{20-22}$

\section{Catalytic study details}

Under an atmosphere of argon, a stainless steel $50 \mathrm{~mL}$ autoclave equipped with a magnetic stir bar, was charged with the corresponding amount of complex (A - D) $(1-10 \mu \mathrm{mol})$, the desired amount of base need/or not $\left(\mathrm{NaBH}_{4}, t\right.$-BuOK or KHDMS) $(5-10 \mu \mathrm{mol})$ and the solvent to be used $(25 \mathrm{~mL})$. A solution of the amide $(1-10 \mathrm{mmol})$ in the solvent $(5$ $\mathrm{mL}$ ) was then added via syringe. The autoclave was purged by three cycles of pressurization/venting with hydrogen (10 bar), then pressurized with hydrogen (50 bar), sealed and disconnected from the hydrogen source. The autoclave was pre-heated to the desired temperature (bath temperature) and the contents stirred. After the corresponding reaction time of $10-48 \mathrm{~h}$, the autoclave was cooled to room temperature and the pressure slowly released. The reaction mixture was filtered through a plug of silica gel. Finally, the reaction mixture was diluted with ethy acetate and analyzed by GC-MS, and then $n$-hexadecane $(50 \mathrm{mg})$ was added as an external standard, and the reaction mixture was diluted with ethyl acetate and analyzed by gas chromatography.

\section{Acknowledgements}

We acknowledge support from the National Natural Science Foundation of China (21476060 and U1362204) and the Nature Science Foundation of Hebei Province (B2014205049). GAS thanks the Chinese Academy of Sciences for a Visiting fellowship.

Keywords: amide or amines; homogeneous catalysis; hydrogenation; base-free; ruthenium

[1] (a) K. Eller, E. Henkes, R. Rossbacher, H. Höke, Ullman's Encyclopedia of Industrial Chemistry; Wiley-VCH: Weinheim, Germany, 2000, Amines, Aliphatic. DOI: 10.1002/14356007.a 02_001; (b) S. A. Lawerence, Ed. Amines: Synthesis, Properties and Applications; Cambridge University Press: Cambridge, U.K., 2006

[2] A. M. Smith, R. Whyman, Chem. Rev. 2014, 114, 5477-5510.
[3] (a) J. Seyden-Penne, Reductions by the Alumino- and Boro-hydrides in Organic Synthesis; John Wiley \& Sons, Inc: New York, 1997; (b) N. L. Lampland, M. Hovey, D. Mukherjee, A. D. Sadow, ACS Catal. 2015, 5, 4219-4226.

[4] For selected recent examples, see: (a) S. Hanada, E. Tsutsumi, Y. Motoyama, H. Nagashima, J. Am. Chem. Soc. 2009,131, 15032-15040; (b) S. Das, D. Addis, S. Zhou, K. Junge, M. Beller, J. Am. Chem. Soc. 2010 132, 1770-1771; (c) S. Das, D. Addis, K. Junge, M. Beller, Chem. - Eur. J. 2011, 17, 12186-12192; (d) S. Park, M. Brookhart, J. Am. Chem. Soc. 2012, 134, 640-653; (e) S. Das, B. Wendt, K. Möller, K. Junge, M. Beller, Angew. Chem., Int. Ed. 2012, 51, 1662-1666; (f) R. C. Chadwick, V. Kardelis, P. Lim, A. Adronov, J. Org. Chem. 2014, 79, 7728-7733.

[5] (a) B. C. Challis, J. A. Challis, In The Chemistry of Amides; Zabicky, J. Patai, S., Eds.; John Wiley \& Sons: London, 1970; (b) K. Ishihara, S. Ohara, H. Yamamoto, J. Org. Chem. 1996, 61,4196-4197; (c) G. W. Bemis, M. A. Murcko, J. Med. Chem. 1999, 42, 5095-5099; (d) R. M. Burk, D. F. Woodward, Drug Dev. Res., 2007, 68, 147-155; (e) C. Cox, T. Lectka, Acc. Chem. Res.2000, 33, 849-858; (f) E. B. Divito, M. Cascio, Chem. Rev. 2013, 113, 7343-7353; (g) M. X. Wang, Acc. Chem. Res. 2015, 48, $602-$ 611; (h) R. M. de Figueiredo, J. S. Suppo and J. M. Campagne, Chem. Rev. 2016, 116, 12029-12122.

[6] S. Werkmeister, K. Junge, M. Beller, Org. Process Res. Dev. 2014, 18, 289-302.

[7] (a) P. A. Dub, T. Ikariya, ACS Catal. 2012, 2, 1718-1741; (b) B. Zhao, Z Han, K. Ding, Angew. Chem., Int. Ed. 2013, 52, 4744-4788.

[8] (a) G. Beamson, A. J. Papworth, C. Philipps, A. M. Smith, R. Whyman, J Catal. 2010, 269, 93-102; (b) G. Beamson, A. J. Papworth, C. Philipps, A M. Smith, R. Whyman, J. Catal. 2011, 278, 228-238; (c) M. Stein, B. Breit, Angew. Chem., Int. Ed. 2013, 52, 2231-2234; (d) R. Burch, C. Paun, X.-M. Cao, P. Crawford, P. Goodrich, C. Hardacre, P. Hu, L. McLaughlin, J. Sá, J. M. Thompson, J. Catal. 2011, 283, 89-97; (e) J. Coetzee, H. G. Manyar, C. Hardacre, D. J. Cole-Hamilton, ChemCatChem 2013, 5, 2843-2847.

[9] A. Fersner, J. M. Karty, Y. Mo, J. Org. Chem. 2009, 74, 7245-7253.

[10] A. A. N. Magro, G. R. Eastham, D. J. Cole-Hamilton, Chem. Commun. 2007, 3154-3156

[11] (a) D. L. Dodds, J. Coetzee, J. Klankermayer, S. Brosinski, W. Leitner D. J. Cole-Hamilton, Chem. Commun. 2012, 48, 12249-12262; (b) J. Coetzee, D. L. Dodds, J. Klankermayer, S. Brosinski, W. Leitner, A. M. Z Slawin, D. J. Cole-Hamilton, Chem. - Eur. J. 2013, 19, 11039-11050; (c) T. vom Stein, M. Meuresch, D. Limper, M. Schmitz, M. Hölscher, J. Coetzee, D. J. Cole-Hamilton, J. Klankermayer, W. Leitner, J. Am. Chem. Soc. 2014 136, 13217-13225; (d) M. Meuresch, S. Westhues, W. Leitner, J. Klankermayer, Angew. Chem. Int. Ed. 2016, 55, 1392-1395; (e) J. R. Cabrero-Antonino, E. Alberico, K. Junge, H. Jungea, M. Beller, Chem. Sci. 2016,7, 3432-3442; (f) M.-L. Yuan, J.-H. Xie, S.-F. Zhu, Q.-L. Zhou, ACS Catal. 2016, 6, 3665-3669; (g) M.-L. Yuan, J.-H. Xie, Q. -L. Zhou, Chem CatChem 2016, 8, 3036-3040.

[12] (a) E. Balaraman, B. Gnanaprakasam, L. J. W. Shimon, D. Milstein, J. Am. Chem. Soc. 2010, 132, 16756-16758; (b) E. Balaraman, C. Gunanathan, J. Zhang, L. J. W. Shimon, D. Milstein, Nat. Chem. 2011, 3, 609-614; (c) E. Balaraman, Y. Ben-David, D. Milstein, Angew. Chem., Int Ed. 2011, 50, 11702-11705; (d) R. Barrios-Francisco, E. Balaraman, Y. Diskin-Posner, G. Leitus, L. J. W. Shimon, D. Milstein, Organometallics, 2013, 32, 2973-2982; (e) T. Zell, D. Milstein, Acc. Chem. Res. 2015, 48 , 1979-1994. (f) J. A. Garg, S. Chakraborty, Y. Ben-David, D. Milstein, Chem. Commun. 2016, 52, 5285-5288

[13] (a) M. Ito, A. Sakaguchi, C. Kobayashi, T. Ikariya, J. Am. Chem. Soc 2007, 129, 290-291; (b) M. Ito, L.W. Koo, A. Himizu, C. Kobayashi, A Sakaguchi, T. Ikariya, Angew. Chem., Int. Ed. 2009, 48, 1324-1327; (c) M. Ito, C. Kobayashi, A. Himizu, T. Ikariya, J. Am. Chem. Soc. 2010, 132, 11414-11415; (d) M. Ito, T. Ootsuka, R. Watari, A. Shiibashi, A. Himizu, T. Ikariya, J. Am. Chem. Soc. 2011, 133, 4240-4242.

[14] (a) S. Saito, T. Miura, I. Held, M. Suzuki, Y. Takada and R. Noyori, Jp. Pat., WO2012102247A1, 2012, p42; (b) T. Miura, I. E. Held, S. Oishi, M. Naruto, S. Saito, Tetrahedron Lett. 2013, 54, 2674-2678.

[15] (a) J. M. John, S. H. Bergens, Angew. Chem. Int. Ed. 2011, 50, 10377 - 
10380; (b) J. M. John, S. Takebayashi, N. Dabral, M. Miskolzie, S. H. Bergens, J. Am. Chem. Soc. 2013, 135, 8578-8584; (c) J. M. John, R. Loorthuraja, E. Antoniuk, S. H. Bergens, Catal. Sci. Technol. 2015, 5, 11811186 .

[16] Y. Kita, T. Higuchi, K. Mashima, Chem. Commun., 2014, 50,1121111213.

[17] J. R. Cabrero-Antonino, E. Alberico, H. J. Drexler, W. Baumann, K. Junge, H. Junge, M. Beller, ACS Catal., 2016, 6, 47-54; (b) V. Papa, J.R. Cabrero-Antonino, E. Alberico, A. Spanneberg, K. Junge, H. Junge, M. Beller, Chem. Sci. 2017, 8, 3576-3585.

[18] (a) L. Shi, X. Tan, J. Long, X. Xiong, S. Yang, Peng. Xue, H. Lv and X. Zhang, Chem. Eur. J. 2017, 23, 546-548; (b) N. M. Rezayee, D. C Samblanet, M. S. Sanford, ACS Catal. 2016, 6, 6377-6383; (c) U.
Jayarathne, Y. Zhang, N. Hazari, W. H. Bernskoetter, Organometallics, 2017, 36, 409-416.

[19] T. Ohkuma, M. Koizumi, K. Muñiz, G. Hilt, C. Kabuto, and R. Noyori, J. Am. Chem. Soc.. 2002, 124, 6508-6509

[20] B. Pan, B. Liu, E. Yue, Q.-B. Liu, X. -Z. Yang, Z. Wang, W. -H. Sun ACS Catal. 2016, 6, 1247-1253.

[21] Z. Wang, X.-Y. Chen, B. Liu, Q.-B. Liu, G. A. Solan, X.-Z. Yang, W.-H. Sun, Catal. Sci. Technol., 2017, 7, 1297-1304.

[22] Z. Wang, B. Pan, Q.-B. Liu, E, Yue, G. A. Solan, Y. Ma, W.-H. Sun, Catal. Sci. Technol., 2017, 7, 1654-1661.

[23] D. Cantillo, Eur. J. Inorg. Chem. 2011, 3008-3013.

[24] X. Yang, ACS Catal. 2013, 3, 2684-2688; (b) X. Chen, Y. Jing, X. Yang, Chem. Eur. J. 2016, 22, 1950-1957. 


\section{COMMUNICATION}

$$
\begin{aligned}
& \mathrm{R}_{1} \overbrace{\substack{\mathrm{N}^{\prime} \\
\mathrm{R}_{3}}}^{\mathrm{O}} \mathrm{R}_{2} \\
& \text { 1. Mild conditions } \\
& \text { 2. Base-free } \\
& \text { 3. Broad substrate scope } \\
& \mathrm{H}_{2} \text { (50 bar), } 120^{\circ} \mathrm{C} \\
& 10-48 \mathrm{~h}, i-\mathrm{PrOH}
\end{aligned}
$$

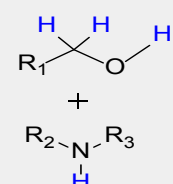$$
\text { H }
$$

Yields up to $99 \%$

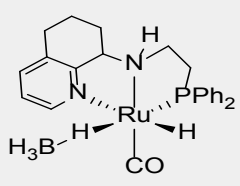

B
Amide hydrogenation: A catalyst loading of between $0.1-1 \mathrm{~mol} \%$ of the PNN$\mathrm{Ru}$ (II) complex B efficiently and selectivity catalyzes the hydrogenation of a broad range of amides under base-free conditions to afford the corresponding alcohols and amines in high yields.
Z. Wang, Y. Li, Q.-B. Liu, G. A. Solan, Y. Ma, W.-H. Sun.

Page No. - Page No.

Direct Hydrogenation of a Broad Range of Amides under Base-free Conditions using an Efficient and Selective PNN-Ru(II) catalyst 